\title{
Erratum: Yuan, W., et al. Genome-Wide Identification of Banana Csl Gene Family and Their Different Responses to Low Temperature between Chilling-Sensitive and Tolerant Cultivars. Plants 2021, 10, 122
}

Weina Yuan ${ }^{1}$, Jing Liu ${ }^{1}$, Tomáš Takáč ${ }^{2} \mathbb{D}$, Houbin Chen ${ }^{1}$, Xiaoquan Li $^{3}$, Jian Meng ${ }^{1}$, Yehuan Tan ${ }^{1}$, Tong Ning ${ }^{1}$, Zhenting $\mathrm{He}^{1}$, Ganjun $\mathrm{Yi}^{4, *}$ and Chunxiang $\mathrm{Xu}^{1, *}$

1 Department of Pomology, College of Horticulture, South China Agricultural University, Guangzhou 510642, China; weina_yuan@stu.scau.edu.cn (W.Y.); liujing@stu.scau.edu.cn (J.L.); hbchen@scau.edu.cn (H.C.); mengjian@stu.scau.edu.cn (J.M.); yehuantan@stu.scau.edu.cn (Y.T.); ningtong@stu.scau.edu.cn (T.N.); hezhenting@stu.scau.edu.cn (Z.H.)

2 Centre of the Region Haná for Biotechnological and Agricultural Research, Department of Cell Biology, Faculty of Science, Palacký University Olomouc, 78375 Olomouc, Czech Republic; tomas.takac@upol.cz

3 Institute of Biotechnology, Guangxi Academy of Agricultural Sciences, Nanning 530007, China; lixiaoquan@gxaas.net

4 Institute of Fruit Tree Research, Guangdong Academy of Agricultural Sciences, Guangzhou 510640, China

* Correspondence: yiganjun@vip.163.com (G.Y.); chxxu@scau.edu.cn (C.X.)

check for updates

Citation: Yuan, W.; Liu, J.; Takáč, T.; Chen, H.; Li, X.; Meng, J.; Tan, Y.; Ning, T.; He, Z.; Yi, G.; et al. Erratum: Yuan, W., et al. Genome-Wide Identification of Banana Csl Gene Family and Their Different Responses to Low Temperature between

Chilling-Sensitive and Tolerant Cultivars. Plants 2021, 10,122. Plants 2021, 10, 654. https://doi.org/ $10.3390 /$ plants 10040654

Received: 16 March 2021

Accepted: 17 March 2021

Published: 30 March 2021

Publisher's Note: MDPI stays neutral with regard to jurisdictional claims in published maps and institutional affiliations.

Copyright: (c) 2021 by the authors. Licensee MDPI, Basel, Switzerland. This article is an open access article distributed under the terms and conditions of the Creative Commons Attribution (CC BY) license (https:// creativecommons.org/licenses/by/ $4.0 /)$.
The authors wish to make the following corrections to this paper [1]:

The affiliation of Tomáš Takáč should have been:

Centre of the Region Haná for Biotechnological and Agricultural Research, Department of Cell Biology, Faculty of Science, Palacký University Olomouc, 78375 Olomouc, Czech Republic; tomas.takac@upol.cz

The authors apologize for any inconvenience that may have been caused.

\section{Reference}

1. Yuan, W.; Liu, J.; Takáč, T.; Chen, H.; Li, X.; Meng, J.; Tan, Y.; Ning, T.; He, Z.; Yi, G.; et al. Genome-Wide Identification of Banana Csl Gene Family and Their Different Responses to Low Temperature between Chilling-Sensitive and Tolerant Cultivars. Plants 2021, 10, 122. [CrossRef] [PubMed] 